\title{
ПОТЕНЦИАЛ ТОКСИНООБРАЗОВАНИЯ ГРИБОВ РОДА Penicillium, ПОРАЖАЮЩИХ ГРУБЫЕ КОРМА
}

\author{
А.А. БУРКИН, Г.П. КОНОНЕНКО, Е.А. ПИРЯЗЕВА
}

Поиск продуцентов микотоксинов среди микроскопических грибов, поражающих растения, сырье животного происхождения, пищевые продукты и корма, был и остается актуальным научным направлением. Многолетнее изучение этой проблемы показало, что угроза возникновения токсикозов человека и животных связана главным образом с микромицетами родов Fusarium, Aspergillus и Penicillium (CAST, 1989). В грубых кормах, составляющих основу рациона жвачных, грибам этих таксонов принадлежит лидирующее положение, однако разнообразие ботанического состава травостоев при заготовке и различия в условиях хранения предполагают проведение региональных обследований с оценкой индивидуальной токсинообразующей способности у видов, преобладающих в составе микобиоты. Мировые данные по этому вопросу крайне ограничены. В России микологический анализ образцов от производственных партий сена и соломы, заготовленных в животноводческих хозяйствах Брянской, Московской, Челябинской областей, показал, что среди фузариевых грибов доминирует высокотоксигенный вид F. sporotrichioides (E.A. Piryazeva c соавт., 2016), а к контаминации циклопиазоновой кислотой, стеригматоцистином и микофеноловой кислотой имеют отношение представители 7 видов рода Aspergillus (G.P. Kononenko с соавт., 2017). Общая пораженность этих кормов грибами рода Penicillium с участием 28 видов превышала 50 \% (Е.А. Пирязева, 2017), но их токсикологическая характеристика не проводилась. В настоящей работе нами впервые показано, что виды P. brevicompactum, P. stoloniferum, $P$. roqueforti, $P$. chrysogenum, $P$. urticae и $P$. expansum из комплекса грибов этого рода могут иметь отношение к обширной и интенсивной контаминации грубых кормов микофеноловой кислотой (МФК), PR-токсином (PR), циклопиазоновой кислотой (ЦПК) и цитринином (ЦИТ). Целью исследования стало определение токсинообразующего потенциала грибов рода Penicillium, широко представленных в микобиоте грубых кормов. Штаммы, относящиеся к 11 видам этого рода, культивировали на панели из 5 питательных сред, включающей агар Чапека-Докса (CDA), сусловый агар (WA), агар Чапека с экстрактом автолизата дрожжей (CYA), сахарозный агар с дрожжевым экстрактом (YES) и увлажненное зерно риса (RG), в течение 7 сут при $25{ }^{\circ} \mathrm{C}$. Далее в экстрактах образцов биомассы измеряли содержания охратоксина А (OA), ЦИТ, МФК, PR, ЦПК, эмодина (ЭМО) и эргоалкалоидов (ЭА) методом непрямого конкурентного иммуноферментного анализа (ELISA) с помощью аттестованных коммерческих и исследовательских тестсистем. На основании полученных результатов виды $P$. aurantiovirens, $P$. palitans, $P$. martensii и $\boldsymbol{P}$. meleagrinum отнесены к непродуцирующим. Среди представителей $\boldsymbol{P}$. cyclopium найдены слабые продуценты МФК и ЦИТ, а также изоляты, не образующие ни один из анализируемых микотоксинов. Интенсивное накопление токсинов (от 10 мкг/г и более) выявили у P. brevicompactum, P. stoloniferum (МФК), P. roqueforti (PR + МФК) и P. chrysogenum (PR), среднее (1-10 мкг/г) - у P. urticae (ЦПК) и P. expansum (ЦИТ). Изоляты, лишенные продуцирующей способности, обнаружили только у $P$. chrysogenum и $P$. expansum, у остальных видов токсинообразование носило устойчивый характер. У представителей $P$. roqueforti, продуцирующих PR в сочетании с МФК, количество МФК было, как правило, меньше, чем PR. В составе грибных метаболитов не выявили ЭМО, ОА и ЭА. Установлено, что выбор панели ростовых сред для тестирования токсинообразования у грибов рода Penicillium - необходимый прием для исчерпывающей оценки их потенциала, при этом, наряду с агаризованными средами, целесообразно использовать субстраты растительного происхождения. Практически у всех продуцирующих видов наибольшая интенсивность накопления токсинов наблюдалась на RG, a для $P$. chrysogenum продуцирование РR удалось выявить лишь на этом субстрате. Обсуждаются особенности профиля токсичных метаболитов у изолятов $\boldsymbol{P}$. cyclopium и $\boldsymbol{P}$. urticae, обусловленные атипичными условиями развития, а также проблема возможного вклада других видов Penicillium в контаминацию грубых кормов микотоксинами.

Ключевые слова: микобиота, корма, виды рода Penicillium, микотоксины.

Поиск продуцентов микотоксинов среди микроскопических грибов, поражающих продовольственные и кормовые культуры, сырье животного происхождения, пищевые продукты и корма был и остается актуальным направлением научных исследований $(1,2)$. Многолетнее изучение этой проблемы показало, что наибольшая угроза возникновения токсикозов связана с микромицетами родов Fusarium, Aspergillus u Penicillium (3, 4). В грубых кормах, составляющих основу рациона жвачных животных, 
грибам этих таксонов принадлежит лидирующее положение, однако разнообразие ботанического состава травостоев и различия условий хранения после заготовки предполагают проведение региональных обследований с оценкой индивидуальной токсинообразующей способности видов из состава микобиоты.

Мировые данные по этому вопросу крайне ограничены. В России при микологическом анализе образцов из производственных партий сена и соломы, заготовленных в животноводческих хозяйствах Брянской, Московской, Челябинской областей, и последующем тестировании изолятов с установленной видовой принадлежностью было показано, что среди представителей фузариевых грибов доминирует высокотоксигенный вид $F$. sporotrichioides (5), а комплекс из 7 видов Aspergillus может иметь отношение к контаминации этих кормов циклопиазоновой кислотой, стеригматоцистином и микофеноловой кислотой (6). По данным микологического обследования производственных партий сена и соломы, заготовленных в Московской и Белгородской областях в 2011 и 2013 годах, более половины проб контаминированы грибами Penicillium, принадлежащими к 28 видам из пяти секций этого рода, при этом 11 видов обнаруживались с частотой 3,8-30,8\% (7).

В настоящей работе нами впервые показано, что виды P. brevicompactum, $P$. stoloniferum, $P$. roqueforti, $P$. chrysogenum, $P$. urticae и $P$. expansum из комплекса грибов этого рода могут иметь отношение к обширной и интенсивной контаминации грубых кормов микофеноловой кислотой, PRтоксином, циклопиазоновой кислотой и цитринином.

Нашей целью стало изучение токсинпродуцирующей способности видов рода Penicillium, преобладающих в составе микобиоты грубых кормов, в экспериментальных условиях, обеспечивающих наиболее полную реализацию биосинтетических возможностей этих грибов.

Mетодика. Исследовали 55 изолятов Penicillium, принадлежащих к видам P. aurantio-virens Biourge, P. brevi-compactum Dierckx, P. chrysogenum Thom, P. cyclopium Westling, P. expansum Link, P. martensii Biourge, P. notatum Westling, $P$. palitans Westling, $P$. roqueforti Thom, $P$. stoloniferum Thom, $P$. urticae Bainier, которые были выделены из грубых кормов, заготовленных в животноводческих хозяйствах Брянской и Московской областей (7), а также 134 штамма тех же видов (коллекция лаборатории микотоксикологии и санитарии кормов ВНИИ ветеринарной санитарии, гигиены и экологии). Видовую идентификацию грибов проводили по культурально-морфологическим признакам согласно таксономической системе (8) с использованием видовых эпитетов из современной номенклатурной базы данных МусоBank (http://www.mycobank.org/) и следующими изменениями в написании: $P$. aurantio-virens (=P. aurantiovirens), P. brevi-compactum (=P. brevicompactum) и $P$. notatum (=P. meleagrinum Biourge) (9).

Оценка токсинообразования грибов включала подготовку инокулюма, субстрата, посев, культивирование, экстракцию и анализ микотоксинов. В качестве посевного материала использовали 10-суточные культуры грибов на агаре Чапека-Докса (CDA, «HiMedia Laboratories Pvt., Ltd.», Индия). Инокулюм примерно равного размера, взятый с поверхности агара микологическим крючком, помещали в 3 повторностях на зерновой субстрат или агаризованные питательные среды в стеклянные флаконы объемом 15 мл с диаметром дна около 18 мм. Зерновым субстратом (RG) был стерильный дробленый рис (1 г), предварительно увлажненный 1 мл воды. Ростовыми средами (по 1,5 мл) служили CDA, сусловый агар (WA, «Liofilchem», Италия), а также агар Чапека с экстрактом автолизата 
дрожжей (CYA) и сахарозный агар с дрожжевым экстрактом (YES) (10), приготовленные из коммерческих компонентов («HiMedia Laboratories Pvt., Ltd», Индия).

После внесения инокулюма флаконы закрывали ватно-марлевыми пробками, которые оборачивали слоем лабораторной пленки (Parafilm “М” РМ-996, «Pechiney Plastic Packaging», США). Культивирование проводили в темноте в течение 7 сут при $25^{\circ} \mathrm{C}$, после чего в каждый флакон добавляли смесь ацетонитрила и воды в объемном соотношении 84:16 и интенсивно встряхивали в начале и конце 14-часовой стационарной экстракции. Содержание охратоксина А (ОА), цитринина (ЦИТ), микофеноловой кислоты (МФК), циклопиазоновой кислоты (ЦПК), PR-токсина (PR), эмодина (ЭМО), эргоалкалоидов (ЭА) в экстрактах определяли методом иммуноферментного анализа (ИФА, ELISA) с помощью аттестованных тест-систем (8), нижние пределы определения соответствовали $85 \%$ связывания антител.

Обработку результатов проводили с помощью описательной статистики в программе Microsoft Excel 2013, результаты выражали как абсолютное содержание микотоксина или средние арифметические полученных значений $(M)$ с ошибкой выборочной средней ( $\pm \mathrm{SEM})$.

Результаты. В последние годы в систематике микроскопических грибов широко используется полифазный подход, который наряду с культурально-морфологическими и молекулярно-генетическими признаками учитывает биохимические характеристики этих организмов. У грибов рода Penicillium по профилю вторичных метаболитов, объединяемых термином экстролиты и включающих физиологически активные вещества и микотоксины, база данных достаточно обширна (12-15), но детектирование веществ в режиме полуколичественной оценки визуально или с использованием инструментальных физико-химических методов не позволяет судить об интенсивности их биосинтеза и полноте получаемой информации. В связи с этим на подготовительном этапе работы для 11 видов Penicillium, наиболее представленных в микобиоте грубых кормов, мы провели количественную оценку токсинообразования коллекционных культур, выделенных из разных объектов, в типовом эксперименте на WA (табл. 1).

1. Токсинообразование у коллекционных штаммов 11 видов грибов рода Penicillium (WA, $23{ }^{\circ} \mathrm{C}, 7$ сут)

\begin{tabular}{|c|c|c|}
\hline Вид Penicillium $(n)$ & Микотоксин & $n^{+}$(количество микотоксина min-max, мкг/г субстрата) \\
\hline P. aurantiovirens (12) & ЦИТ & $4(0,1-0,3)$ \\
\hline P. brevicompactum (7) & МФК & $7(40-440)$ \\
\hline P. chrysogenum (8) & PR & $4(0,8-40)$ \\
\hline & ЭМО & $2(0,1 ; 0,6)$ \\
\hline P. cyclopium (24) & PR & $1(0,7)$ \\
\hline & МФК & $3(30,40,50)$ \\
\hline P. expansum (3) & ЦИТ & $2(13,16)$ \\
\hline P. martensii (24) & ЦПК & $1(0,6)$ \\
\hline P. meleagrinum (3) & - & - \\
\hline P. palitans $(11)$ & - & - \\
\hline P. roqueforti (16) & $\begin{array}{l}\mathrm{PR}+\mathrm{MФK} \\
\mathrm{PR}\end{array}$ & $\begin{array}{c}7(35-135)+(0,2-25) \\
1(20)\end{array}$ \\
\hline P. stoloniferum (3) & МФК & $3(2,22,76)$ \\
\hline P. urticae (23) & $\begin{array}{l}\text { ЦПК } \\
\text { МФК }\end{array}$ & $\begin{array}{c}17(0,2-4) \\
1(40)\end{array}$ \\
\hline
\end{tabular}

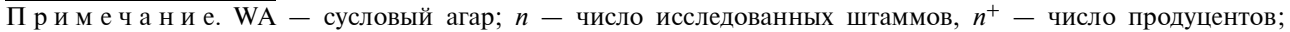
ЦИТ - цитринин, МФК - микофеноловая кислота, ЦПК - циклопиазоновая кислота, ЭМО - эмодин, PR - PR токсин; прочерк означает, что продуценты не выявлены.

У всех видов, кроме P. meleagrinum и P. palitans, были найдены продуценты ЦИТ, МФК, ЦПК и ЭМО. Однако исчерпывающая реализация 
потенциала наблюдалась только у $P$. brevicompactum и $P$. stoloniferum, у остальных видов встречались штаммы, не способные к продуцированию: так, ЦИТ был найден лишь в четырех из 12 штаммов P. aurantiovirens, a ЦПК у P. martensii - лишь в одном из 24 (см. табл. 1). Среди P. chrysogenum, $P$. cyclopium и $P$. urticae были выявлены продуценты разных токсинов, большинство штаммов P. roqueforti синтезировали совместно PR и МФК, один штамм - только PR. Это указывало на существование у них внутривидовых хемотипов или подвидов со специфическим профилем микотоксинов (13) либо атипичных форм с особенностями метаболических путей.

Для оценки потенциала токсинообразования грибов, выделенных из грубых кормов, были сформированы группы по 5 культур каждого из 11 видов и составлена панель из 5 питательных сред. Учитывая опыт изучения метаболического ответа грибов из тех же объектов, были взяты WA и RG, ранее использованные для грибов рода Fusarium (5), а также CDA, примененный для тестирования Aspergillus (6). Из агаризованных сред, рекомендованных для культивирования и идентификации Penicillium (10, 1215), были выбраны CYA и YES, на которых два коллекционных штамма P. stoloniferum демонстрировали более интенсивное накопление МФК (со-

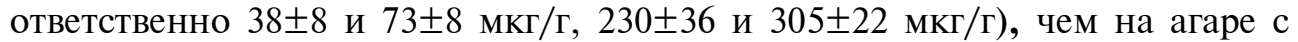
экстрактом солода (МЕА) $(2,0 \pm 0,4$ и $22 \pm 3$ мкг/г).

В этих экспериментах у изолятов P. aurantiovirens $(n=5)$ и $P$. palitans $(n=5)$ токсинообразование мы не обнаружили. Такой результат был ожидаемым, поскольку у коллекционных штаммов первого вида продукция ЦИТ оказалась крайне слабой, а у второго вообще отсутствовала (см. табл. 1). Тем не менее важно отметить то, что в таксономических работах многократно сообщалось о способности P. palitans синтезировать ЦПК (15), поэтому следует допустить вероятность некоторой неопределенности в идентификации этого вида по морфологическим признакам. У P. martensii $(n=5)$ и $P$. meleagrinum $(n=5)$ удалось определить ЦИТ только для единичных изолятов на WA и RG в количествах менее 1 мкг/г, а ЦПК не обнаружили, хотя она была найдена в малом количестве у одного из 24 коллекционных штаммов P. martensii (см. табл. 1). У P. cyclopium токсинообразование также было слабо выраженным и многовариантным - на CDA, WA и RG один изолят образовывал небольшие количества МФК (0,3-1,0 мкг/г), а второй - ЦИТ (0,03-0,8 мкг/Г), при этом по данным хемотаксономических исследований этот вид вообще не способен к биосинтезу анализируемых микотоксинов (15). Полученные результаты указывали на то, что вклад этих пяти видов ( $P$. aurantiovirens $P$. cyclopium $P$. martensii P. meleagrinum и P. palitans) в контаминацию грубых кормов санитарно значимыми микотоксинами незначителен.

Для остальных шести видов ( $P$. brevicompactum, P. stoloniferum, P. roqueforti, $P$. chrysogenum, $P$. urticae и $P$. expansum) подтвердилась высокая продукция МФК, PR (более 10 мкг/г) и средняя (до 10 мкг/г) - ЦПК и ЦИТ (табл. 2). Как и следовало ожидать, для P. brevicompactum и P. stoloniferum был характерен устойчивый биосинтез МФК, других токсинов из числа анализируемых не обнаружили. Значительная интенсивность накопления этого токсина позволила отнести указанные изоляты к высокоактивным продуцентам и весьма вероятным источникам контаминации кормов (16).

Для всех изолятов P. roqueforti из грубых кормов была подтверждена способность продуцировать PR в сочетании с МФК (см. табл. 2), которую считают отличительной чертой подвида P. roqueforti var. roqueforti (13). Реaкция тестированных культур на питательную среду оказалась весьма своеобразной. На обедненном субстрате CDA интенсивность накопления PR была 
2. Токсинообразующая способность изолятов 6 видов грибов рода Penicillium из грубых кормов на агаризованных средах и зерне риса $\left(25^{\circ} \mathrm{C}, 7\right.$ сут)

\begin{tabular}{|c|c|c|c|c|c|c|}
\hline \multirow{2}{*}{ Микотоксин } & \multirow{2}{*}{ № изолята } & \multicolumn{5}{|c|}{ Количество микотоксина, мкг/г субстрата ( $M \pm \mathrm{SEM})$} \\
\hline & & CDA & WA & CYA & YES & $\mathrm{RG}$ \\
\hline & \multicolumn{6}{|c|}{ P. brevicompactum $\left(n^{+} / n=6 / 6\right)$} \\
\hline \multirow[t]{6}{*}{ МФК } & $40 / 2$ & $6,0 \pm 0,9$ & $6,0 \pm 1,1$ & $76 \pm 15$ & $110 \pm 20$ & $124 \pm 25$ \\
\hline & $181 / 1$ & $9,0 \pm 1,8$ & $17 \pm 3$ & $34 \pm 7$ & $174 \pm 35$ & $302 \pm 70$ \\
\hline & $254 / 1$ & $8,0 \pm 1,6$ & $15 \pm 3$ & $28 \pm 6$ & $100 \pm 18$ & $169 \pm 32$ \\
\hline & $4 / 3$ & - & $128 \pm 30$ & $126 \pm 32$ & $120 \pm 18$ & $722 \pm 101$ \\
\hline & $340 / 1$ & - & $81 \pm 10$ & $144 \pm 25$ & $192 \pm 25$ & $1117 \pm 91$ \\
\hline & $16 / 1$ & - & $53 \pm 8$ & $19 \pm 4$ & $72 \pm 8$ & $792 \pm 19$ \\
\hline \multicolumn{7}{|c|}{ P. chrysogenum $\left(n^{+} / n=4 / 5\right)$} \\
\hline \multirow{4}{*}{ PR } & $172 / 1$ & 0 & 0 & 0 & 0 & $14 \pm 3$ \\
\hline & $373 / 1$ & 0 & 0 & 0 & 0 & $13 \pm 2$ \\
\hline & $592 / 1$ & 0 & 0 & 0 & 0 & $5,7 \pm 1,3$ \\
\hline & $639 / 5$ & 0 & 0 & 0 & 0 & $2,0 \pm 0,4$ \\
\hline \multicolumn{7}{|c|}{ P. expansum $\left(n^{+} / n=1 / 5\right)$} \\
\hline \multirow[t]{2}{*}{ ЦИТ } & $88 / 4$ & $5,0 \pm 0,8$ & $3,0 \pm 0,5$ & $7,0 \pm 1,7$ & $3,3 \pm 0,6$ & $11 \pm 2)$ \\
\hline & \multicolumn{6}{|c|}{ P. roqueforti $\left(n^{+} / n=5 / 5\right)$} \\
\hline PR + МФК & $88 / 2$ & $50 \pm 9 /$ & $2,8 \pm 0,5 /$ & $4,3 \pm 0,7 /$ & $5,7 \pm 1,8 /$ & $150 \pm 24 /$ \\
\hline (значение & $88 / 2$ & $1 \pm 0$ & $3,0 \pm 0,5$ & $3,1 \pm 0,6$ & $0,13 \pm 0,02$ & $63 \pm 13$ \\
\hline приведены & $118 / 1$ & $45 \pm 8 /$ & $0,9 \pm 0,2 /$ & $1,7 \pm 0,3 /$ & $2,0 \pm 0,3 /$ & $95 \pm 14 /$ \\
\hline \multirow[t]{7}{*}{ через косую) } & & $1 \pm 0$ & $2,5 \pm 0,5$ & $0,9 \pm 0,2$ & $0,13 \pm 0,02$ & $48 \pm 8$ \\
\hline & & $48 \pm 9 /$ & $10 \pm 2 /$ & $6,7 \pm 1,0 /$ & $3,0 \pm 0,4 /$ & $780 \pm 72 /$ \\
\hline & $648 / 5$ & $0,2 \pm 0,0$ & $3,3 \pm 0,6$ & $4,7 \pm 0,9$ & $0,07 \pm 0,01$ & $67 \pm 14$ \\
\hline & $393 / 1$ & $29 \pm) /$ & $2,1 \pm 0,4 /$ & $50 \pm 9 /$ & $4,7 \pm 0,8 /$ & $329 \pm 43 /$ \\
\hline & $390 / 1$ & $0,3 \pm 0,1$ & $5,3 \pm 1,0$ & $8,7 \pm 1,5$ & $3,7 \pm 0,6$ & $98 \pm 17$ \\
\hline & $557 / 1$ & $22 \pm 3 /$ & $4,7 \pm 0,6 /$ & $34 \pm 6 /$ & $2,3 \pm 0,4 /$ & $224 \pm 38 /$ \\
\hline & & 0 & $2,7 \pm 0,4$ & $3,4 \pm 0,7$ & $0,1 \pm 0,02$ & $55 \pm 8$ \\
\hline \multicolumn{7}{|c|}{ P. stoloniferum $\left(n^{+} / n=5 / 5\right)$} \\
\hline \multirow[t]{6}{*}{ МФК } & $631 / 4$ & 0 & $11 \pm 2$ & $43 \pm 5$ & $64 \pm 13$ & $100 \pm 20$ \\
\hline & $631 / 3$ & 0 & $14 \pm 4$ & $41 \pm 10$ & $91 \pm 10$ & $175 \pm 39$ \\
\hline & $317 / 4$ & $10 \pm 2$ & $193 \pm 39$ & $115 \pm 22$ & $151 \pm 30$ & $1330 \pm 250$ \\
\hline & $602 / 1$ & $5,7 \pm 1,7$ & $24 \pm 5$ & $40 \pm 6$ & $272 \pm 54$ & $332 \pm 60$ \\
\hline & $602 / 3$ & 0 & $9 \pm 2$ & $23 \pm 4$ & $110 \pm 20$ & $145 \pm 22$ \\
\hline & \multicolumn{6}{|c|}{ P. urticae $\left(n^{+} / n=5 / 5\right)$} \\
\hline \multirow[t]{5}{*}{ ЦПК } & $349 / 1$ & $1 \pm 0$ & $0,1 \pm 0$ & $5,7 \pm 0,6$ & $2,3 \pm 0,5$ & $4,0 \pm 0,8$ \\
\hline & $584 / 4$ & $2,0 \pm 0,2$ & $0,1 \pm 0$ & $12 \pm 2$ & $1 \pm 0$ & $10 \pm 2$ \\
\hline & $201 / 1$ & $2 \pm 0$ & $0,1 \pm 0$ & $7 \pm 1$ & $3,3 \pm 0,6$ & $12 \pm 1$ \\
\hline & $216 / 5$ & 0 & 0 & $0,43 \pm 0,07$ & $0,23 \pm 0,05$ & $0,37 \pm 0,07$ \\
\hline & $434 / 4$ & $2 \pm 0$ & $0,33 \pm 0,06$ & $5,3 \pm 0,6$ & $5 \pm 0$ & $6,7 \pm 1,3$ \\
\hline $\begin{array}{l}\text { П р и м е ч а н } \\
\text { автолизата дро } \\
\text { исследованных } \\
\text { ЦПК - циклог }\end{array}$ & $\begin{array}{l}\text { е. CDA - a } \\
\text { жей, YES - } \\
\text { штаммов, } n^{+} \\
\text {аазоновая ки }\end{array}$ & Чапека-Д & $\begin{array}{l}\text { WA - су } \\
\text { с дрожжев } \\
\text { тов; ЦИТ } \\
\text { Ксин. Про }\end{array}$ & $\begin{array}{l}\text { ый агар, С } \\
\text { экстрактом } \\
\text { итринин, } \\
\text { означает, }\end{array}$ & $\begin{array}{l}\text { - агар Чап } \\
\text { - зерно } \\
\text { - микофе } \\
\text { икотоксин }\end{array}$ & $\begin{array}{l}\text { с экстракто } \\
; n-\text { числ } \\
\text { вая кислот } \\
\text { пределяли. }\end{array}$ \\
\hline
\end{tabular}

существенно выше, чем на WA, хотя ранее сообщалось, что у изолятов этого вида из силосованных кормов различий в токсинообразовании на CDA и WA практически не было, а МФК также находили в значительно меньших количествах, чем PR (17). Причиной этого несоответствия вполне могло быть использование в указанной работе субстрата, приготовленного в лабораторных условиях из пивного сусла, и наблюдаемое резкое усиление биосинтеза PR на аналоге коммерческой стандартизированной среды, несомненно, заслуживает внимания. Метаболический ответ изолятов P. roqueforti на CYA и YES в целом был слабо выраженным и сходным по соотношению количеств PR и МФК, различия между штаммами отмечались только на CYA, а на остальных агаризованных средах были незначительными. Тем не менее недавно при тестировании на YES c визуальным ТСХ-детектированием штаммы P. roqueforti из разных сортов сыра, совместно продуцирующие PR и MФК, имели значительные различия по интенсивности накопления PR и слабые - по МФК (18). Вполне возможно, что морфологически идентичные культуры из разных объектов имеют генетически детерминированные особенности и, как следствие, показывают неодинаковые метаболические ответные реакции на изменение условий роста. 
Все представители P. urticae продемонстрировали способность синтезировать ЦПК, хотя и с накоплением ниже 10 мкг/г. Это согласуется с данными ТСХ-тестирования (синтетическая среда, $28{ }^{\circ} \mathrm{C}, 8$ сут) 13 изолятов той же видовой принадлежности (выделены из сушеных бобов и макаронных изделий), которые также оказались продуцентами этого токсина (19). В соответствии с новым таксономическим подходом P. urticae считают синонимом P. griseofulvum Dierckx (14), и ЦПК называют в числе специфических метаболических маркеров (15).

У видов P. chrysogenum и P. expansum полной реализации потенциала не наблюдалось. Все представители P. chrysogenum, кроме одного, продуцировали PR в широком количественном диапазоне и только на зерновом субстрате (см. табл. 2). Отсутствие токсинообразования на широкой панели агаризованных сред было неожиданным, поскольку в упомянутой выше работе (12) сообщалось, что на CYA и YES 50-80 \% изолятов этого вида из 87 изученных способны к биосинтезу PR, а большинство штаммов из Всероссийской коллекции микроорганизмов Института биохимии и физиологии микроорганизмов им. Г.К. Скрябина РАН образовывали этот токсин на ЧДА, хотя и в малых количествах (17).

Из пяти штаммов $P$. expansum только один синтезировал ЦИТ на всех средах (см. табл. 2), такое же частичное продуцирование отмечали при тестировании коллекционных штаммов на WA (см. табл. 1). По-видимому, «нулевые» хемотипы этого вида гриба встречаются в кормовых объектах достаточно часто. Однако следует заметить, что при ТСХ-скрининге (CYA, YES) P. expansum из разных источников практически у всех штаммов различного происхождения (95-99 \%, $n=91)$ детектировали ЦИТ (9).

Полученные результаты показывают, что выбор панели ростовых сред - необходимый прием для исчерпывающей оценки токсинообразования микроскопических грибов и использование стандартизированных коммерческих сред для изучения биохимических процессов не предпочтительно, а скорее обязательно. Особого внимания заслуживают качественные различия в ответных реакциях грибов при смене ростовой среды (как, например, у P. roqueforti и P. chrysogenum). В последние годы для этих видов подробно изучено строение участков генома, ответственных за синтез токсичных метаболитов, и показана важная роль внекластерных регуляторов, активность которых определяется условиями роста организма, в частности свойствами ростовых сред (21-23). В наших экспериментах с грибами рода Penicillium на зерне риса происходило более активное накопление MФК, PR, ЦПК и ЦИТ. Только на этом субстрате четыре штамма P. chrysogenum из пяти продуцировали PR, который считают одним из его хемотаксономических маркеров. Расширение поиска в ряду естественных субстратов позволит в будущем создать аналогичные рецептуры контролируемого состава, обеспечивающие максимальную реализацию метаболического потенциала грибов.

Представленные в работе данные свидетельствуют о том, что виды P. brevicompactum, P. stoloniferum, P. roqueforti, P. chrysogenum, P. urticae и $P$. expansum могут иметь отношение к обширной и интенсивной контаминации грубых кормов МФК, PR, ЦПК и ЦИТ (24). Однако следует также учитывать тот факт, что для грибов этого рода известно формирование измененных морфологических фенотипов адаптационного характера при обитании в антропогенно нарушенных и экстремальных условиях (25). Так, при тестировании некоторых штаммов P. cyclopium и P. urticae на WA нами были найдены высокоактивные продуценты нетипичного для них метаболита - МФК (см. табл. 1). Объектами выделения этих культур были сле- 
жавшиеся пласты рассыпных кормов, подвергшихся длительному самосогреванию. В описанном случае вполне возможно несоответствие (искажение) видовых диагнозов, установленных по микро- и макроморфологическим признакам.

Более того, вряд ли правомерно полностью исключать участие других представителей рода Penicillium, поскольку виды, выбранные для оценки как наиболее представленные в микобиоте, составляют лишь менее половины от общего их числа. Так, для изолята, отнесенного к редкому в этих кормах виду P. steckii Zaleski (=P. steckii K.M. Zalesski) (9), (=P. citrinum Thom) (26), показано активное продуцирование ЦИТ (собственные неопубликованные данные).

Другие часто встречающиеся в грубых кормах микотоксины - OA, ЭМО и ЭА у испытанных изолятов не были обнаружены. Тем не менее среди редко встречающихся видов идентифицирован P. viridicatum (7), для которого доказано существование нескольких линий с отчетливыми различиями в характере токсинообразования (в статусе вида или подвида), в их числе - P. verrucosum и P. nordicum, продуцирующие OA (27). Частое обнаружение и высокое содержание в кормах ЭМО пока не находят убедительных объяснений в микологическом аспекте. Преобладают доводы в пользу отнесения ЭМО к ассоциированным метаболитам высших растений и специфических грибов-эндофитов (28), хотя в числе продуцентов этого метаболита называют несколько видов Penicillium, в частности $P$. islandicum, P. brunneum, P. janthinellum и P. herquei (29). Источники обширной контаминации грубых кормов ЭА также остаются неясными. Среди таксонов, причисленных к нетрадиционным источникам пептидных ЭА, указаны только несовершенные грибы родов Aspergillus, Botrytis, Curvularia, Geotrichum, низшие грибы (Cinnighamella blakesleana, Mucor hiemalis, Rhyzopus spp.), а также эндофиты трав, относящиеся к сумчатым грибам (Balansia spp., Epichloe typhina, Hypomyces aurantius, Sepedonium sp.) (30). Однако недавно у изолята из злаково-бобового сена заготовки 2005 года из Пермского края, идентифицированного по культуральным признакам как P. palitans при тестировании на WA, показано активное накопление этих метаболитов в количестве 2,7士0,2 мкг/г (собственные неопубликованные данные).

Нельзя исключать, что грибы Penicillium имеют отношение к контаминации этих кормов и другими токсинами из числа часто встречающихся. Так, в отдельном эксперименте у изолята P. steckii и двух изолятов P. urticae после культивирования на MEA, CYA и YES в небольших количествах найден альтернариол (собственные неопубликованные данные), ранее также сообщалось о способности $P$. coprophilum синтезировать этот токсин (15).

Важным итогом представленной работы стало понимание того, что совершенствование методологии оценки токсинообразования у микроскопических грибов должно быть продолжено. За многие десятилетия наукой накоплен богатый опыт в изучении токсинообразования у микроскопических грибов, однако информация о потенциале популяций, жизнедеятельность которых связана с сельскохозяйственными растениями, до сих пор крайне ограничена, а доступные экспериментальные данные часто становятся предметом неверных толкований и выводов. Одна из основных причин этого - недооценка сложности проблемы и отсутствие единой общепринятой методологии проведения исследовательских работ. Оценку токсинпродуцирующей способности культур целесообразно проводить в унифицированных условиях и избегать использования питательных сред и условий, не позволяющих проводить сравнение результатов (31). В послед- 
ние годы все большее признание получает несложная технология краткосрочного культивирования на питательных субстратах с последующим скрининговым анализом, обеспечивающим широкие диапазоны измерения. Для дифференциации культур по интенсивности токсинообразования уже предложен разграничительный уровень 10 мкг/г, а также соответствующие термины - слабые продуценты с меньшим накоплением и высокоактивные, образующие такие метаболиты в количествах выше этого порогового значения (32). Соотношение числа продуцентов к общему числу изученных штаммов, которое обозначают как $n^{+} / n$ и выражают в процентах, принято называть потенциалом токсинообразования у анализируемойй совокупности культур, а диапазон накопления, обозначаемый как $\min -$ среднее-max (мкг/г), - интенсивностью токсинообразования. При выявлении внутри выборки продуцентов с качественными различиями в продуктах метаболизма может быть использован термин «характер токсинообразования».

Грибы рода Penicillium, преобладающие в составе микобиоты грубых кормов, продуцируют микотоксины, которые в организме жвачных, подавляя активность микроорганизмов, могут приводить к серьезным нарушениям функции рубца и провоцировать развитие интоксикации у животных (33). Кроме того, микроскопические грибы, наряду с бактериями и простейшими, активно участвуют в усвоении полисахаридов клеточных стенок кормовых растений. Недавно показано, что в частично переваренной целлюлозе из сычуга коров доминируют грибы родов Aspergillus и Penicillium, и в их числе P. brevicompactum (34). Последствия продолжительного анаэробного обитания токсигенных грибов в пищеварительном тракте этих животных на каждой из четырх последовательных стадий могут быть весьма опасными и нуждаются в подробном изучении.

Таким образом, 6 видов грибов рода Penicillium (P. brevicompactum, P. stoloniferum, P. roqueforti, P. chrysogenum, P. urticae и $P$. expansum), представленные в составе микобиоты грубых кормов, способны активно продуцировать комплекс микотоксинов и могут иметь отношение к обширной и интенсивной контаминации кормов цитринином, микофеноловой кислотой, PR-токсином и циклопиазоновой кислотой. Установлено, что выбор панели ростовых сред для тестирования токсинообразования грибов рода Penicillium необходим для исчерпывающей оценки их потенциала, при этом, наряду с агаризованными средами, целесообразно использовать субстраты растительного происхождения. Знание биосинтетических возможностей микроскопических грибов важно не только для решения таких глобальных практических проблем, как обеспечение сохранности животных и получение безопасной агропродукции, но и для дальнейшего развития фундаментальных молекулярно-генетических и эволюционных представлений о жизнедеятельности этих организмов.

\section{ЛИТЕРАТУРА}

1. Pitt J.I. Toxigenic fungi and mycotoxins. British Medical Bulletin, 2000, 56: 184-192 (doi: 10.1258/0007142001902888).

2. Egbuta M.A., Mwanza M., Babalola O.O. Health risks associated with exposure to filamentous fungi. International Journal of Environmental Research and Public Health, 2017, 14: 719 (doi: 10.3390/ijerph14070719).

3. Mycotoxins: economic and health risks. Task Force Report. $R$ 116. November 1989. CAST, Ames, 1989. Режим доступа: http://www.cast-science.org/publications/?mycotoxins_economic_and_health_risks\&show=product\&productID=2869. Дата обращения: 10.06.2019.

4. Milićević D.R., Škrinjar M., Baltić T. Real and perceived risks for mycotoxin contamination in foods and feeds: challenges for food safety control. Toxins, 2010, 2: 572-592 (doi: 10.3390/toxins2040572).

5. Piryazeva E.A., Kononenko G.P., Burkin A.A. Affection of coarse fodders by toxigenic Fusari- 
um fungi. Agricultural Biology, 2016, 51(6): 937-945 (doi: 10.15389/agrobiology.2016.6.eng).

6. Kononenko G.P., Piryazeva E.A., Zotova E.V., Burkin A.A. Toxicological characteristics of Aspergillus fungi from coarse fodders. Agricultural Biology [Sel'skokhozyaistvennaya Biologiya], 2017, 52(6): 937-945 (doi: 10.15389/agrobiology.2017.6.eng).

7. Пирязева Е.А. Грибы рода Penicillium в грубых кормах. Проблемы ветеринарной санитарии, гигиены и экологии, 2017, 4(24): 42-45.

8. Raper K.B., Thom C., Fennell D.J. A manual of the Penicillia. Williams \&Wilkins Company, Baltimore, 1949.

9. MycoBank database. Fungal databases, Nomenclature \& Species Banks. Режим доступа: http://www.mycobank.org/mycotaxo.aspx. Без даты.

10. Introduction to food- and airborne fungi /R.A. Samson, E.S. Hoekstra, J.S. Frisvad, O. Filtenborg (eds.). CBS, Utrecht, 2000.

11. ГОСТ 31653-2012 Корма. Метод иммуноферментного определения микотоксинов. М., 2012.

12. Frisvad J.C., Filtenborg O. Classification of Terverticillate penicillia based on profiles of mycotoxins and other secondary metabolites. Appl. Environ. Microbiol., 1983, 46(6): 1301-1310.

13. Frisvad J.C., Filtenborg O. Terverticillate penicillia: chemotaxonomy and mycotoxin production. Mycologia, 1989, 81: 837-861 (doi: 10.2307/3760103).

14. Frisvad J.C., Samson R.A. Polyphasic taxonomy of Penicillium subgenus Penicillium. A guide to identification of food and air-borne terverticillate Penicillia and their mycotoxins. Studies in Mycology, 2004, 49: 1-174.

15. Frisvad J.C., Smedsgaard J., Larsen T.O., Samson R.A. Mycotoxins, drugs and other extrolites produced by species in Penicillium subgenus Penicillium. Studies in Mycology, 2004, 49: 201-241.

16. Burkin A.A., Kononenko G.P. Producers of mycophenolic acid in ensiled and grain feeds. $A p-$ plied Biochemistry and Microbiology, 2010, (46)5: 545-550 (doi: 10.1134/S0003683810050145).

17. Burkin A.A., Kononenko G.P., Kochkina G.A., Ozerskaya S.M. Enzyme-linked immune sorbent assay for PR-toxin in taxonomical assessment of fungi belonging to the genus Penicillium Link. Applied Biochemistry and Microbiology, 2007, 43(4): 453-458 (doi: 10.1134/S0003683807040175).

18. Fernández-Bodega M.A., Mauriz E., Gymez A., Martín J.F. Proteolytic activity, mycotoxins and andrastin A in Penicillium roqueforti strains isolated from Cabrales, Valdeyn and BejesTresviso local varieties of blue-veined cheeses. International Journal of Food Microbiology, 2009, 136: 18-25 (doi: 10.1016/j.ijfoodmicro.2009.09.014).

19. Trucksess M.W., Mislivec P.B., Young K., Bruce V.R., Page S.W. Cyclopiazonic acid production by cultures of Aspergillus and Penicillium species isolated from dried beans, corn meal, macaroni and pecans. Journal of Association of Official Analytical Chemists, 1987, 70(1): 123-126.

20. Rao V.K., Shilpa P., Girisham S., Reddy S.M. Incidence of mycotoxigenic penicillia in feeds of Andhra Pradesh, India. International Journal for Biotechnology and Molecular Biology Research, 2011, 2(2): 46-50.

21. Brock N.L. Dickschat J.S. PR-toxin biosynthesis in Penicillium roqueforti. ChemBio Chem, 2013, 14(10): 1189-1193 (doi: 10.1002/cbic.201300254).

22. Hidalgo P.I., Ullán R.V., Albillos S.M., Montero O., Fernández-Bodega M.A., Garcia-Estrada C., Fernández-Aguado M., Martin J.-F. Molecular characterization of the PR toxin gene cluster in Penicillium roqueforti and Penicillium chrysogenum: cross talk of secondary metabolite pathways. Fungal Genetics and Biology, 2014, 62: 11-24 (doi: 10.1016/j.fgb.2013.10.009).

23. Hidalgo P.I., Poirier E., Ullán R.V., Piqueras J, Meslet-Cardière L., Coton E., Coton M. Penicillium roqueforti PR toxin gene cluster characterization. Applied Genetics and Molecular Biotechnology, 2017, 101: 2043-2056 (doi: 10.1016/j.fgb.2013.10.009).

24. Кононенко Г.П., Буркин А.А. О контаминации микотоксинами партий сена в животноводческих хозяйствах. Сельскохозяйственная биология, 2014, 4: 120-126 (doi: 10.15389/agrobiology.2014.4.120rus).

25. Kozlovsky A.G., Zhelifonova V.P., Antipova T.V. Secondary metabolites in the taxonomy of fungi of the subgenus Penicillium. Microbiology, 2009, 78(5): 618-623 (doi: $10.1134 / \mathrm{S} 0026261709050142)$.

26. Index Fungorum. Режим доступа: http://www.indexfungorum.org/Names/Names.asp. Без даты.

27. Larsen T.O., Svendsen A., Smedsgaard J. Biochemical characterization of ochratoxin Aproducing strains of the genus Penicillium. Applied and Environmental Microbiology, 2001, 67(8): 3630-3635 (doi: 10.1128/AEM.67.8.3630-3635.2001).

28. Izhaki I. Emodin - a secondary metabolite with multiple ecological functions in higher plants. New Phytologist, 2002, 155(2): 205-217 (doi: 10.1046/j.1469-8137.2002.00459.x).

29. Refai M., Abo El-Yazid H., Tawakkol W. Monograph on the genus Penicillium. A guide for historical, classification and identification of penicillin, their industrial applications and detrimental effects, 2015. Режим доступа: https://scholar.cu.edu.eg/?q=hanem/files/monograph_on_the_genus_penicillium.pdf. Без даты.

30. Козловский А.Г. Нетрадиционные продуценты эргоалкалоидов (обзор). Прикладная биохимия и микробиология, 1999, 35(5): 536-545.

31. Винокурова Н.Г., Иванушкина Н.Е., Кочкина Г.А., Аринбасаров М.У., Озерская С.М. Синтез микофеноловой кислоты грибами рода Penicillium Link. Прикладная биохимия $u$ микробиология, 2005, 41(1): 95-98. 
32. Varga J., Rigo K., Lamper C., Téren J., Szaby G. Kinetics of ochratoxin A production in different Aspergillus species. Acta Biologica Hungarica, 2002, 53(3): 381-388 (doi: 10.1556/ABiol.53.2002.3).

33. Gallo A., Giuberti G., Frisvad J.C., Bertuzzi T., Nielsen K.F. Review on mycotoxin issues in ruminants: occurrence in forages, effects of mycotoxin ingestion on health status and animal performance and practical strategies to counteract their negative effects. Toxins, 2015, 7: 30573111 (doi: 10.3390/toxins7083057).

34. Obire O., Okigbo R.N. Ojim C.F. Fungal population and diversity in partially digested cellulose from the abomasum of beef cows. Journal of Agricultural Technology, 2010, 6(4): 783-792.

\title{
Всероссийский НИИ ветеринарной санитарии, гигиены и экологии - филиал ФГБНУ ФНЦ ВИЭВ РАН, 123022 Россия, г. Москва, Звенигородское ш., 5, e-mail: aaburkin@mail.ru, kononenkogp@mail.ru $\bowtie$, piryazeva01@yandex.ru
}

Поступила в редакцию 18 июля 2018 года

Sel'skokhozyaistvennaya biologiya [Agricultural Biology], 2019, V. 54, № 3, pp. 616-625

\section{TOXIN-PRODUCING FUNGI OF THE GENUS Penicillium IN COARSE FODDERS}

\section{A.A. Burkin, G.P. Kononenko, E.A. Piryazeva}

\begin{abstract}
All-Russian Research Institute for Veterinary Sanitation, Hygiene and Ecology - Branch of FSC ARRIEV RAS, 5, Zvenigorodskoe sh., Moscow, 123022 Russia, e-mail aaburkin@mail.ru, kononenkogp@mail.ru ( $\square$ corresponding author), piryazeva01@yandex.ru
\end{abstract}

ORCID:

Burkin A.A. orcid.org/0000-0002-5674-2818

Kononenko G.P. orcid.org/0000-0002-9144-615X

Piryazeva E.A., orcid.org/0000-0001-5443-3213

The authors declare no conflict of interests

Received July 18, 2018

doi: 10.15389/agrobiology.2019.3.616eng

\section{Abstract}

The search for toxin-producing microscopic fungi, affecting plant and animals products, food and feed continues to be relevant in scientific research. A long-term study of this problem has shown that the threat of the occurrence of toxicoses of humans and animals is associated mainly with micromycetes of genus Fusarium, Aspergillus and Penicillium (CAST, 1989). In coarse feed, which form the basis of the ration of ruminants, these fungi have a leading position. Among Fusarium fungi the highly toxic species F. sporotrichioides dominates in hay and straw (E.A. Piryazeva et al., 2016), and 7 species of Aspergillus are capable to contaminate that with CPA, STE and MPA (G.P. Kononenko et al., 2017). The purpose of this work was to elucidate the toxin-forming potential of 11 species of the genus Penicillium fungi which prevail in mycobiota of coarse feed. The strains were cultured for 7 days at $25^{\circ} \mathrm{C}$ on a panel including Czapek Dox agar (CDA), wort agar (WA), Czapek Yeast Autolysate Agar (CYA), yeast extract sucrose agar (YES) and moistened rice grain (RG). Further, in the extracts, the amounts of ochratoxin A (OA), citrinin (CIT), mycophenolic acid (MPA), PR-toxin (PR), cyclopiazonic acid (CPA), emodin (EMO) and ergot alkaloids (EA) were determined by indirect competitive enzyme-linked immunosorbent assay (ELISA) using certified commercial and research test systems. On the basis of obtained results, the species $P$. aurantiovirens, $P$. palitans, as well as $P$. martensii and $P$. meleagrinum are classified as non-producing. Among the representatives of $P$. cyclopium, we found weak producers of MPA and CIT, as well as isolates that do not form any of the analyzed mycotoxins. High accumulation $(10 \mu \mathrm{g} / \mathrm{g}$ and more $)$ is revealed in P. brevicompactum, P. stoloniferum (MPA), P. roqueforti (PR + MPA), P. chrysogenum (PR) and average level $(1-10 \mu \mathrm{g} / \mathrm{g})$ is characteristic of P. urticae (CPA) and P. expansum (CIT). Isolates lacking production capacity were found only among $P$. chrysogenum and $P$. expansum, toxin production by other species was stable. In the representatives of $P$. roqueforti, producing jointly PR and MPA, the amount of MPA was, as a rule, less than PR. EMO, OA and EA in the metabolites of fungi were not found. In this paper it was shown for the first time that the species P. expansum, $P$. brevicompactum, P. stoloniferum, $P$. roqueforti, $P$. chrysogenum and $P$. urticae from a typical complex of fungi of this genus can be related to extensive and intensive contamination of coarse fodder by CIT, MPA, PR and CPA. It has been established that the use of a growth media panel for testing the toxicity of Penicillium fungi is an indispensable technique for an exhaustive assessment of their potential, and, in addition to agar media, it is expedient to use substrates of plant origin. Virtually all producing species had the highest intensity of toxin accumulation on RG, and for $P$. chrysogenum, PR production could be detected only on this substrate. Specific features of the profile of toxic metabolites in isolates belonging to one species are discussed, as well as the problem of the possible contribution of other species of Penicillium to the contamination of coarse fodder by mycotoxins.

Keywords: mycobiota, feeds, Penicillium fungi, mycotoxins. 